\title{
Organization and Function of the Blood-Brain Barrier in Drosophila
}

\author{
Tobias Stork, ${ }^{1}$ Daniel Engelen, ${ }^{1}$ Alice Krudewig, ${ }^{1}$ Marion Silies, ${ }^{1}$ Roland J. Bainton, ${ }^{2}$ and Christian Klämbt ${ }^{1}$ \\ ${ }^{1}$ Institut für Neurobiologie, Universität Münster, D-48149 Münster Germany, and ${ }^{2}$ Department of Anesthesia and Perioperative Care, University of \\ California, San Francisco, California 94158-2517
}

\begin{abstract}
The function of a complex nervous system depends on an intricate interplay between neuronal and glial cell types. One of the many functions of glial cells is to provide an efficient insulation of the nervous system and thereby allowing a fine tuned homeostasis of ions and other small molecules. Here, we present a detailed cellular analysis of the glial cell complement constituting the blood-brain barrier in Drosophila. Using electron microscopic analysis and single cell-labeling experiments, we characterize different glial cell layers at the surface of the nervous system, the perineurial glial layer, the subperineurial glial layer, the wrapping glial cell layer, and a thick layer of extracellular matrix, the neural lamella. To test the functional roles of these sheaths we performed a series of dye penetration experiments in the nervous systems of wild-type and mutant embryos. Comparing the kinetics of uptake of different sized fluorescently labeled dyes in different mutants allowed to conclude that most of the barrier function is mediated by the septate junctions formed by the subperineurial cells, whereas the perineurial glial cell layer and the neural lamella contribute to barrier selectivity against much larger particles (i.e., the size of proteins). We further compare the requirements of different septate junction components for the integrity of the blood-brain barrier and provide evidence that two of the six Claudin-like proteins found in Drosophila are needed for normal bloodbrain barrier function.
\end{abstract}

Key words: Drosophila; blood- brain barrier; glial cells; septate junction; development; perineurial glia; subperineurial glia

\section{Introduction}

Any complex nervous system comprises two different cell types. Whereas the different types of neurons perceive and integrate information, glial cells set the stage to provide the environment required for normal functionality of neurons (Freeman and Doherty, 2006). Indeed increasingly complicated neuronal connectivity is linked to the relative number of glial cells (Granderath and Klämbt, 1999; Lemke, 2001). Compared with $>50 \%$ in mammals, only $10 \%$ of all neural Drosophila cells are of glial nature making it a particularly good model system to study glial development and function (Edenfeld et al., 2005; Freeman and Doherty, 2006).

Previous work suggested surprising parallels between the molecular mechanisms instructing Drosophila and mammalian glial differentiation. In both systems, glial differentiation is dependent on regulation of pre-mRNA splicing. Mutations in the splicing regulator Quaking lead to a dysmyelination phenotype in mice (Sidman et al., 1964; Ebersole et al., 1996). Similarly, mutations in the Drosophila ortholog how disrupt glial differentiation by af-

Received June 11, 2007; revised Nov. 13, 2007; accepted Dec. 4, 2007.

This work was supported by grants from the Deutsche Forschungsgemeinschaft to C.K. M.S. acknowledges a fellowship from the Boehringer Ingelheim foundation. We are grateful for the many fly stocks that were sent by the Bloomington stock center. We are thankful to our colleagues who provided additional flies stocks used in this study: R. Fehon for coracle and nervana2 alleles, A. Giangrande for $g \mathrm{~cm}$ mutants, M. Gonzales-Gaitan for flp-out strains, B. Altenhein for the fas //Gal4 (Mz507) strain, H. Aberle for the chaGal4 strain, and U. Thomas for UAS:EGFPDlgS97 flies.

Correspondence should be addressed to Christian Klämbt, Institut für Neurobiologie, Universität Münster, Badestrasse 9, D-48149 Münster, Germany. E-mail: klaembt@uni-muenster.de.

DOI:10.1523/JNEUROSCI.4367-07.2008

Copyright $\odot 2008$ Society for Neuroscience $\quad$ 0270-6474/08/280587-11\$15.00/0 fecting splicing (Edenfeld et al., 2006). One of the splicing targets of the HOW complex is neurexinIV, which encodes a septate junction component homologous to the mammalian Caspr protein. Moreover, septate junctions formed by myelinating glia at the paranodal junctions as well as those formed by Drosophila glial cells rely on sets of evolutionary conserved membrane proteins: Caspr/NeurexinIV, Contactin, and Neurofascin155/Neuroglian (Baumgartner et al., 1996; Bhat et al., 2001; Girault and Peles, 2002; Poliak and Peles, 2003; Faivre-Sarrailh et al., 2004; Banerjee et al., 2006). Thus, not only the regulation of glial differentiation, but also the final realization of glial differentiation appears to be directed by evolutionary conserved mechanisms.

Despite the growing knowledge on early gliogenesis and subsequent differentiation, we do, however, know amazingly little about the normal morphology and function of the different glial cell types found in a fly nervous system (Ito et al., 1995; Van De Bor and Giangrande, 2002; Freeman and Doherty, 2006). Here, we present a detailed morphological characterization of the different glial cell layers using electron microscopy and confocal analyses of single-labeled glial cells. Inward from a dense outer extracellular matrix is a perineurial sheath of astrocyte-like shaped cells, which are able to divide throughout larval development. Below the perineurium are the septate junction forming subperineurial glial cells. The organization of the more inner glial layers slightly differs in the PNS and CNS. In the PNS, inner wrapping glial cells insulate individual axons of the nerves at the end of larval development, whereas in the CNS cortex and neuropile glia are found below the subperineurial glial cell layer 
where they ensheath neuronal cell bodies, axonal tracts and the dendritic compartments (Pereanu et al., 2005).

To assay the functionality of the blood-brain barrier, we determined the kinetics of dye uptake for small and large dextran molecules in wild-type and several mutant animals, which suggested that the barrier function is mostly mediated by the subperineurial cells, whereas the other glial cell layers contribute to barrier selectivity against much larger particles.

\section{Materials and Methods}

Genetics. The following fly strains were used in this study: $\mathrm{gcm}^{N 7-4}$ (Vincent et al., 1996); moody ${ }^{\Delta 17}$ (Bainton et al., 2005); $n r x I V^{4304}$ (Baumgartner et al., 1996); nrxIV ${ }^{E P 604}$; rrg $^{14}$ (Bloomington Stock Center, Bloomington, IN); $n r v 2^{k 13315}$ (Genova and Fehon, 2003); $\operatorname{coracle}^{5}$ (Lamb et al., 1998); $D f(3 R) E D 5020$ to remove contactin (Faivre-Sarrailh et al., 2004); sinu ${ }^{N W U 7}$ (Wu et al., 2004); Df(1)RR79 to remove the Claudin CG6398; $D f(2 R) M 60 E$ to remove the Claudin CG3770; $D f(2 R)$ nap2 to remove the Claudin CG1298; Df(3R)Excel6192 to remove the Claudin CG6982; pck ${ }^{E A 97}$ (megatrachea) (Behr et al., 2003); 454 NeurexinIV:GFP, $125 \mathrm{La}$ chesin:GFP (Edenfeld et al., 2006); 173 nervana2:GFP (U. Lammel, unpublished observations); UAS:GFP; UAS:laminGFP; UAS:flp, nervana2Gal4 (Bloomington stock center); $p v r^{7.1}$ Viking:GFP (Olofsson and Page, 2005); 43Gal4 (Bloomington stock center); c527Gal4 (Hummel et al., 2002); FasIIGal4 (Mz507) (B. Altenhein, personal communication); chaGal4 (Salvaterra and Kitamoto, 2001); and SPG:Gal4 (Bainton et al., 2005). All deficiencies were obtained from the Bloomington stock collection. To label individual glial cells, we followed a flip-out strategy (Struhl and Basler, 1993). The following sources of Flp recombinase were used: repo:Gal4 UAS:flp and a direct repo:flp fusion (Silies et al., 2007). The following flipout constructs were used: UAS $>C D 2$ yellow $^{+}>m C D 8 G F P$ and tub $>64>\mathrm{Gal} 4$ (Wong et al., 2002). In addition we generated Mosaic analysis with a repressible cell marker (MARCM) clones (Lee and Luo, 1999) using repo:flp; repoGal4 UAS:actinGFP FRT80/FRT80 Gal80.

Immunohistochemistry and electron microscopic analyses. Antibodies [22C10, Fasciclin II (Fas II), Repo] were obtained from the Developmental Studies Hybridoma bank (Iowa City, IA). Anti- $\beta$ Gal (Cappel, Cochranville, PA), anti-GFP (Invitrogen, Eugene, OR), and anti-HRP Cy5 (Dianova, Hamburg, Germany) antisera were used according to the manufacturer's instructions. Fixation and treatment of tissues for immunohistochemistry was performed according to standard procedures. For electron microscopic (EM) analyses, embryos were fixed in glutaraldehyde-saturated $N$-heptane and the vitelline membrane was removed by hand. Stage 17 embryos were injected with $4 \%$ PFA and immediately opened on both ends. They were then fixed overnight in $4 \%$ PFA. Larval tissues were also fixed in $4 \%$ PFA at $4^{\circ} \mathrm{C}$ overnight. After a fixation in $2 \% \mathrm{OsO}_{4}$ for $1 \mathrm{~h}$ at room temperature and $2 \%$ uranylacetate treatment for $30 \mathrm{~min}$ at room temperature in the dark, tissues were embedded in epon as described previously (Stollewerk et al., 1996; Stollewerk and Klämbt, 1997), but acrolein treatment was omitted. Ultrathin sections were imaged with a Zeiss (Oberkochen, Germany) EM900 with an SIS Morada digital camera. Fluorescently labeled specimens were analyzed using a Zeiss 510 LSM; orthogonal sections were taken using the Zeiss image browser.

Dextran uptake. The following dextrans were used: $2.5 \mathrm{~mm} 10 \mathrm{kDa}$ Texas red conjugated dextran (Invitrogen) in $\mathrm{H}_{2} \mathrm{O} ; 0.4 \mathrm{~mm} 70 \mathrm{kDa}$ FITC conjugated anionic dextran (Invitrogen) in $\mathrm{H}_{2} \mathrm{O}$; and $0.01 \mathrm{~mm} 500 \mathrm{kDa}$ FITC conjugated anionic dextran (Invitrogen) in $\mathrm{H}_{2} \mathrm{O}$. Dextran solutions were injected into stage 17 embryos according to standard procedures (Schwabe et al., 2005). The genotype of the embryos was determined using green fluorescent protein (GFP)-labeled balancer chromosomes. To calculate the uptake of the fluorescence label into the nervous system we generated stacks of confocal images ( $2 \mu \mathrm{m}$ thick; through the entire nervous system) at 2, 10,20, and 30 min after injection with a Zeiss 5 Live LSM (set at four frames per second with $512 \times 512$ resolution). The laser settings were identical throughout the experiments and were controlled using a Convallaria majalis slide provided by Zeiss. The mean density of pixel intensity (ranging from 0 to 255 ) reflecting the dextran uptake was determined in an identical area of five injected embryos per genotype using the Zeiss LSM software. To determine the uptake kinetics, the same region was measured over time.

\section{Results}

\section{Formation of the blood-brain barrier}

All Drosophila glial cells, except the midline glia, express the repo gene (Xiong et al., 1994; Lee and Jones, 2005). Several repopositive glial cell layers cover the Drosophila nervous system. Two distinct cell types, the perineurial and the subperineurial glia form the outer cell layers. They separate axons and neuronal cell bodies, which are surrounded by cortex and wrapping glia, from the high potassium concentration in the hemolymph to allow normal electrical conductance. To characterize individual glial cells we followed either a flip-out strategy and expressed the Flp recombinase in all glial cells of flies carrying different flip-out constructs or we generated MARCM clones [using either a repoflp strain (Silies et al., 2007) or a repoGal4 UASflp strain]. These procedures result in the random, but specific labeling of few glial cells in every animal. The MARCM technology requires cell division to generate labeled cell clones whereas the flip-out technology can also be applied in postmitotic cells (Struhl and Basler, 1993; Lee and Luo, 1999). In previous reports these outer glial cell layers were often considered as single morphological unit termed surface glia, peripheral glia or perineurium and no comprehensive assignment of the morphological and functional diversity has been made (Bellen et al., 1998; Leiserson et al., 2000; Sepp et al., 2000; Bainton et al., 2005; Schwabe et al., 2005; Freeman and Doherty, 2006).

\section{The neural lamella}

A dense network of extra cellular matrix, called neural lamella, surrounds both the central and the peripheral nervous system and can be detected by a protein trap insertion into the collagen IV locus (Fig. 1A). The neural lamella can be detected from embryonic stage 16 onwards (supplemental Fig. $1 A, B$, available at www.jneurosci.org as supplemental material). No distinction can be made between the matrix covering the CNS and peripheral nervous system, indicating that the neural lamella is a continuous, relatively unstructured layer. In mutants with reduced hemocyte motility no lamella is formed (supplemental Fig. $1 C$, available at www.jneurosci.org as supplemental material) (Olofsson and Page, 2005).

\section{The perineurial layer}

The perineurial glial cells are located just below the neural lamella. We did not identify a gene trap exclusively expressed in these cells. However, the Gal4 driver c527 (Hummel et al., 2002) shows preferential activity in this cell type as can be seen in orthogonal sections of third instar peripheral nerves (Fig. $1 B$ ). Cells within the perineurial glial cell layer of the CNS exhibit a star-like shape with many thin cell protrusions within the perineurial layer itself, which never invade into the neural tissue (Fig. 2A,B). Based on several MARCM clones comprising only perineurial glial cells (Fig. 2B), we conclude that these cells can divide considerably during larval stages. In the PNS, only few perineurial glial cells are found in the first instar stage. In third larval instar nerves, perineurial cells divide and cover the nerve. Here they appear elongated with fine cell processes (Fig. 3C,f, arrowhead).

\section{The subperineurial layer}

The second glial cell layer is formed by the subperineurial cells. These cells specifically express the moody gene (Bainton et al., 

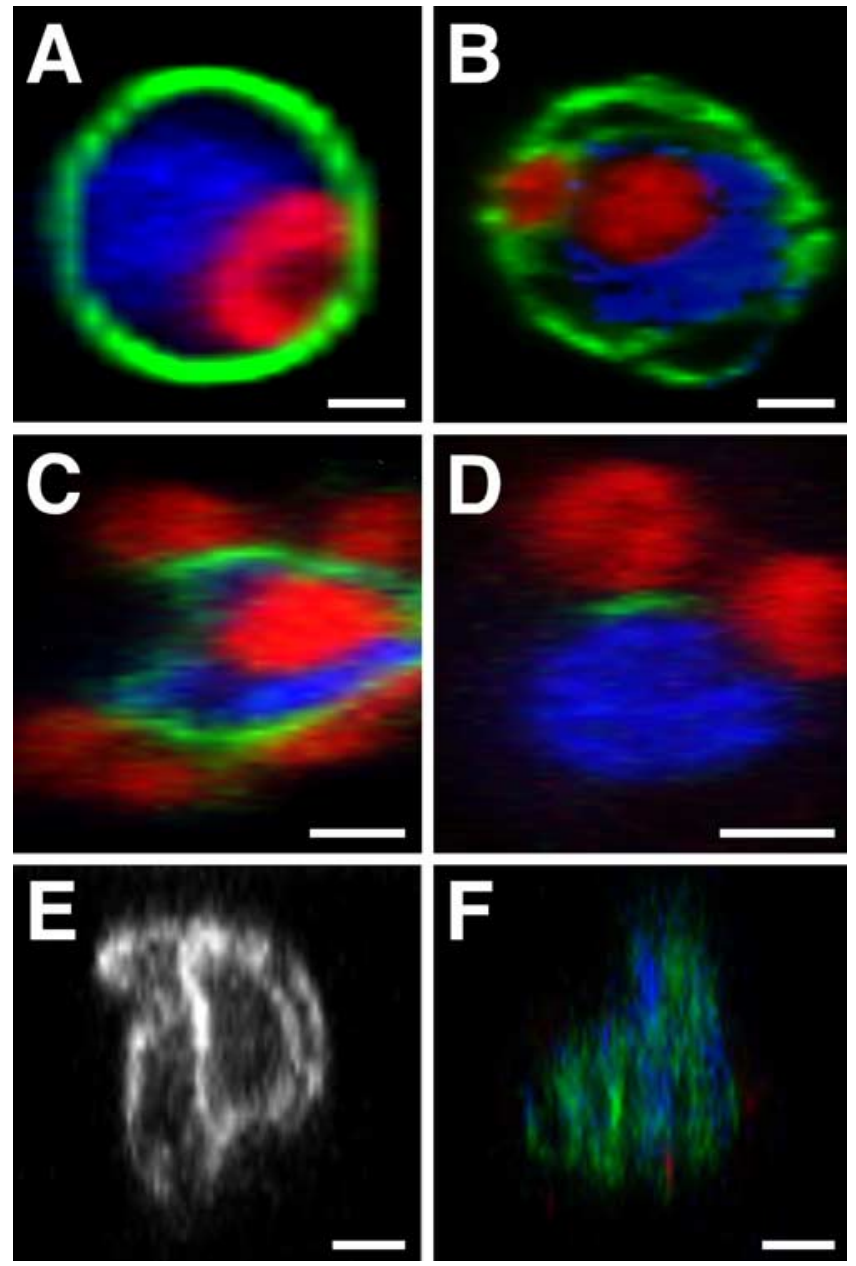

Figure 1. Anatomy of the peripheral nerve. Orthogonal sections through stacks of confocal images of nerves of third instar larvae stained for HRP expression (blue), Repo expression (red) and GFP expression (green). $\boldsymbol{A}$, The GFP-gene trap insertion in Collagen IV (Viking) labels the neural lamella. $\boldsymbol{B}$, The Gal4 driver strain (527 activates expression of CD8:GFP predominantly in the perineurial cells, which are just below the neural lamella. $\boldsymbol{C}$, The SPG-Gal4 driver activates CD8:GFP expression in the subperineurial cells that tightly encircle the axonal fascicles (blue). Note the occurrence of a glial cell nucleus in the fascicle $(\boldsymbol{B}, \boldsymbol{C})$. D, The GFP-gene trap insertion in neurexinIV (\#454) labels a thin stripe along the entire axonal fascicle. $\boldsymbol{E}$, Repo-Gal4 activates CD8:GFP expression in all glial cells. Note, that some GFP expression is also visible within the nerve. $\boldsymbol{F}$, A GFP-gene trap insertion in the nervana 2 gene labels glial cell membranes within the fascicle. Scale bars: $2 \mu \mathrm{m}$

2005; Schwabe et al., 2005) and we used moody promoter sequences to generate the subperineurial glia (SPG)-Gal4 driver (Fig. 1C). Generally, the subperineurial cells form a thin layer below the perineurial cells (Figs. $1 C, 2 D, F$ ). In the CNS, single subperineurial cells labeled by the flip-out technique appear always as very large, hexagonally arranged cells often extending $40-80 \mu \mathrm{m}$ in diameter (Fig. $2 C-E$ ). Subperineurial cells in the PNS are very large as well and can form autocellular junctions (see below).

\section{The wrapping glia}

The final glial cell layer in the PNS comprises the wrapping glia. During late embryonic and early larval stages, these glial cells initially contact fascicles of sensory and motor axons and only later during the third larval stage ensheath almost every single axon resembling the appearance of Schwann cells in Remak bundles of the mammalian PNS (see below) (Nave and Salzer, 2006). Along the peripheral nerves, only three nervana2-Gal4 (Sun et al.,
1999) positive wrapping glial cells are found (Fig. $1 F$, supplemental Fig. 2, available at www.jneurosci.org as supplemental material). These cells extend long and thin processes that wrap individual axons (Fig. $3 A, B, a-d$ ). In a given section of a peripheral nerve two to three glial cell processes can be detected (see Figs. 3, 6) (see below). In the CNS, the inner glial layer is more complex and comprises cortex glia that insulate neuronal cell bodies as well as the initial segments of the axons and neuropil glia that ensheathes the axon fascicles and presumably contacts individual synapses in dendritic compartments (Younossi-Hartenstein et al., 2003; Pereanu et al., 2005). Further details on these glial cell classes will be presented elsewhere.

\section{Sensory and motor axons are individually wrapped in the periphery}

The PNS harbors two distinct axonal classes: the sensory axons that project into the CNS and the motor axons that project outwards from the CNS to the muscle fibers in the periphery. To address whether wrapping glial cells keep sensory and motor components separate, we used either a Gal4 driver that is active in most sensory neurons (43Gal4) and counterstained with anti-Fas II antibodies to label motor axons (Fig. $4 A, C$ ) or we used a gene trap insertion into the fas II gene mimicking fas II gene expression in all motoneurons (\#397) (U. Lammel, unpublished observation) and then counterstained with anti-Futsch antibodies that label all sensory axons and only few motor axons (Hummel et al., 2000) (Fig. 4B,D). Confocal analyses of such embryos indicate that indeed the motor and sensory axons are kept in distinct fascicles (Fig. 4A-D). To test the organization of sensory and motor axons in third instar larvae we used a fasGal4 driver to label motor axons and a chaGal4 driver to visualize sensory axons (Fig. $4 E, F)$. Again, confocal analyses demonstrated a clear separation of the two modalities within the segmental nerves.

\section{Ultrastructural analysis}

To corroborate the above findings we determined the ultrastructural appearance of the different glial cells at embryonic and larval stages. At the electron microscopic level, the structure of the neural lamella appeared identical in the CNS and the PNS (Fig. 5). In embryonic stages, only few perineurial cells were identified. They generally develop numerous processes that strictly stay within the glial layer and mediate extensive cell-cell contacts among the perineurial cells (Fig. $5 C, D)$. In contrast to later developmental stages, the perineurial cells do not cover the entire circumference of the nervous system (Figs. 5A, F, G, 6).

Below the perineurial cells lies the subperineurium. Electron microscopic analyses confirm the flat cell shape of the subperineurial glia and demonstrate that these cells establish septate junctions with each other (Figs. 5E, 6A, inset) (see below). In the CNS, the subperineurial cells are not in contact with axons, which instead are wrapped by neuropile glia. In the PNS of the first instar larvae, however, the subperineurial glial cells can be in direct contact with axons as they form a sheath around the entire nerve (Fig. $5 F, G$ ).

In late embryos, the wrapping glia separates sensory and motor axon fascicles. The wrapping glia has not yet started to ensheath individual axons (Fig. $5 A, B$ ). In first instar larvae, the wrapping glia starts to ensheath individual peripheral axons (Fig. $5 F, G$ ). During the third instar larvae stage, the wrapping glia has individually ensheathed most axons and the contact between axons and subperineurial cells is nearly completely lost (Fig. 6). 
In the periphery, the subperineurial glial cells form autocellular junctions

Septate junctions formed by the subperineurial cells have long been considered to be the structural basis for the blood-brain barrier (Treherne, 1962; Treherne and $\mathrm{Pi}$ chon, 1972; Carlson et al., 2000). Injection of electron opaque tracer molecules demonstrated that these molecules could easily penetrate through the neural lamella, but did not progress beyond the junctional complexes (Lane and Treherne, 1972). More recently, it was shown that the G-protein coupled receptor Moody is expressed specifically by subperineurial glial cells and that loss of moody function results in both a reduced formation of septate junctions and a leaky blood-brain barrier (Bainton et al., 2005; Schwabe et al., 2005).

In support of this we found septate junctions prominently in the subperineurial glial layer in serial EM sections in both, the CNS and the PNS (Figs. 5, 6; supplemental Fig. 3, available at www.jneurosci.org as supplemental material). Tracking of glial cell membranes in serial electron microscopic cross sections of peripheral nerves shows that generally one subperineurial cell is detected which exhibits prominent autocellular septate junctions (Fig. 6). To further support the notion that the subperineurial glial cells generate septate junctions we expressed a GFP-tagged Discs large protein that in epithelial cells faithfully localizes to septate junctions. After expression of the GFP::DlgS97 fusion (Bachmann et al., 2004) in the subperineurial glial cell layer (using the SPG-Gal4 driver), the GFP::DlgS97 fusion protein was recruited into septate junction-like structures that resemble those labeled by the neurexinIV gene trap insertion (Figs. $6 B, C, 7)$. In the periphery, septate junctions are visualized as a thin single line closely following the axonal fascicles, and only rarely we noted ring-like structures around the nerve representing contact zones of two subperineurial glial cells (Fig. $7 A, B)$, resembling the junctional organization in trachea (Fig. 7C) (Ribeiro et al., 2004). This further demonstrates that only a few subperineurial cells populate the nerve and that they predominantly form autocellular septate junctions as suggested in the electron microscopic analyses.

\section{Physiological role of the different} barrier layers

The different glial cells analyzed above comprise the functional blood-brain barrier. The integrity of this barrier can be measured after injection of labeled dextran molecules into the hemolymph (Bainton et al., 2005; Schwabe et al., 2005). Furthermore, the use of differently sized dextran allows
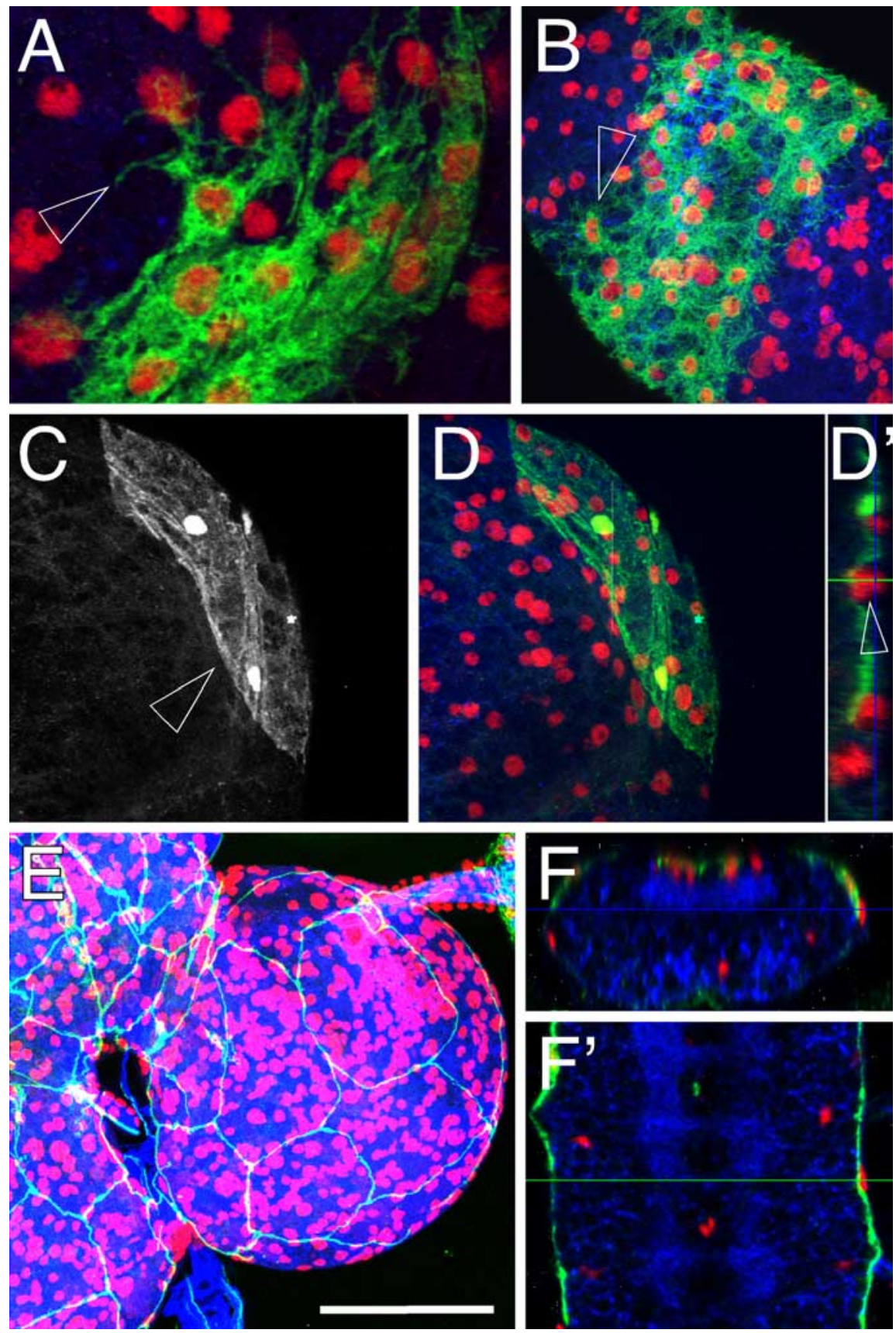

Figure 2. Morphology of perineurial and subperineurial glial cells. To label individual cells or cell clones Flp expression was induced in glial cells (repoFlp; repoGal4 UASactin::GFP; Gal80 FRT19A/FRT19A). Larval nervous systems were stained for Repo expression (red) and GFP expression (green), and neurons were labeled with anti HRP (blue). $\boldsymbol{A}$, MARCM cell clone of perineurial glial cells in the third instar larval brain. Note the extensive cell protrusions generated by these cells (arrowhead). $\boldsymbol{B}$, A large MARCM clone consisting exclusively of perineurial cells in the abdominal part of the ventral nerve cord of a third instar larval brain. Perineurial glial cells show many fine filopodia-like cell protrusions (arrowhead). C, Small flip-out clone of subperineurial glial cells (repoGal4; UASflp; UAS $>C D 2 y^{+}>m$ CD8GFP). In this confocal section, two of the nuclei can be identified. In contrast to the perineurial glia, the subperineurial cells never form lateral filopodia-like extensions (arrowhead). $\boldsymbol{D}, \boldsymbol{D}^{\prime}$, The large and flat subperineurial glial cells are covered by an outer layer of glial cells, the perineurium. $\boldsymbol{D}^{\prime}$, In an orthogonal section, as indicated by the white line in $\boldsymbol{D}$, Repo-positive glial nuclei are seen apically to the GFP expressing glial cells (arrowhead). $E$, Projection of confocal stacks of a third instar brain lobe stained for Repo (red), HRP (blue) and expression of NeurexinIV::GFP fusion protein that is confined to the septate junctions of subperineurial cells. Scale bar, $85 \mu \mathrm{m}$. $\boldsymbol{F}, \boldsymbol{F}^{\prime}$, CNS of a stage 16 embryo stained for Neurexin::GFP and Repo expression. Note that some Repo-positive nuclei are located apically to the GFP expressing subperineurial cells.

addressing a possible size selectivity of the barrier. To determine the kinetics of dextran uptake we used a Zeiss 5 Live LSM (see Materials and Methods). This allowed us to directly follow and quantify the dextran uptake in living embryos. 

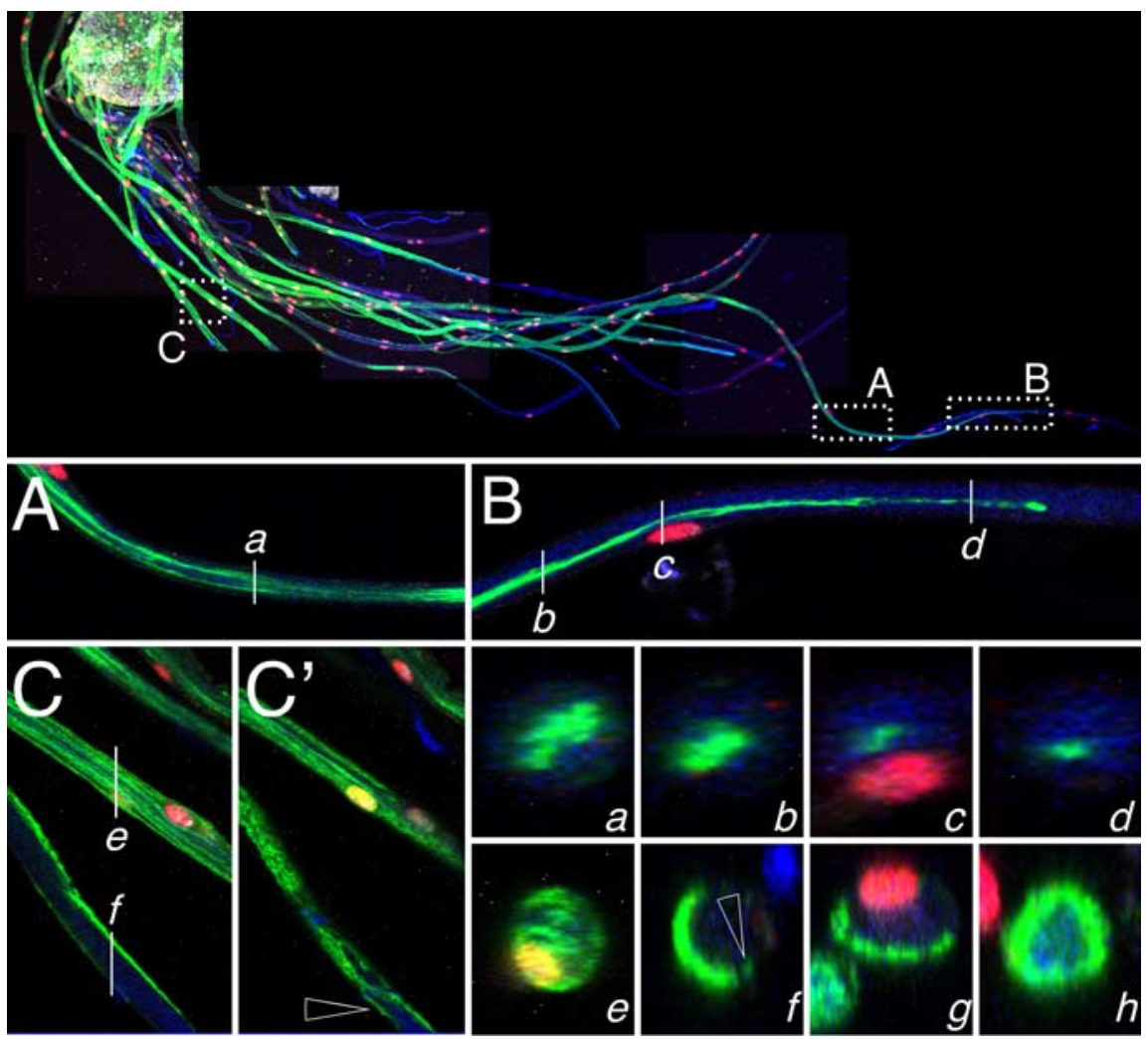

Figure 3. Glial cells in the peripheral nervous system. To label individual cells or cell clones Flp expression was induced in glial cells of animals carrying a UAS $>C D 2 y^{+}>m$ CD8GFP construct. Larval nervous systems were stained for HRP expression (blue), Repo expression (red), and GFP expression (green). The top panel shows an overview of a ventral nerve cord with attached peripheral nerves. The boxed areas are shown in higher magnification in $\boldsymbol{A}-\boldsymbol{C}$. $\boldsymbol{A}, \boldsymbol{B}$, Peripheral nerve with a GFP labeled single wrapping glial cell. This glial cell spreads over at least $200 \mu \mathrm{m}$. The position of four orthogonal sections is indicated by small letters $(\boldsymbol{a}-\boldsymbol{d})$. The wrapping glial cells can form very thin processes that extend over long distances. $\boldsymbol{C}, \boldsymbol{C}^{\prime}$, The upper nerve shows a wrapping glia that has covered almost the entire fascicle. The lower nerve shows a perineurial glia clone. The arrowhead denotes a fine cell process. $\boldsymbol{C}^{\prime}$, Different confocal $z$-section of the same region as shown in $\boldsymbol{C}$. Note the processes of the perineurial glial cell that cover the nerve. The small letters indicate the position of the orthogonal sections $(\boldsymbol{e}, \boldsymbol{f})$. Fine perineurial cell processes are indicated by an arrowhead $\left(\boldsymbol{C}^{\prime}, \boldsymbol{f}\right), \boldsymbol{g}, \boldsymbol{h}$, Two additional examples of perineurial glial cells.

When we injected a fluorescently labeled $10 \mathrm{kDa}$ neutral dextran into stage 17 wild-type embryos, only little amount of fluorescence could be detected in the ventral nerve cord with the laser settings used in the experiment (Fig. 8A). Almost no increase in the level of fluorescence can be detected within a $30 \mathrm{~min}$ observation period. To genetically remove all components of the blood-brain barrier, we used homozygous mutant glial cells missing $(\mathrm{gcm})$ embryos. In these animals, all glial cells, except the midline glial cells, are routed toward a neuronal fate (Hosoya et al., 1995). When we injected labeled 10 $\mathrm{kDa}$ dextran into stage 17 homozygous mutant $\mathrm{gcm}$ embryos, high levels of fluorescence were detected within the nerve cord immediately after injection and no increase in the level of fluorescence were seen within $30 \mathrm{~min}$ (Fig. 8D,P). This reflects the complete loss of the blood-brain barrier in $\mathrm{gcm}$ mutants.

To address the function of the subperineurium we analyzed mutants known to affect the formation of septate junctions and compared their phenotypic consequences with those of $\mathrm{gcm}$ mutants. Mutants that remove important structural components of the septate junctions in epithelia such as neurexinIV mutants also show a severe disruption of the integrity of the blood-brain barrier (Baumgartner et al., 1996; Schwabe et al., 2005; Strigini et al., 2006). Indeed, fluorescently labeled $10 \mathrm{kDa}$ dextran penetrated with very similar kinetics into the ventral nerve cords of $n r x I V$ or $g \mathrm{~cm}$ mutant embryos (Fig. 8G,P). Because on the EM level the morphology of the outer
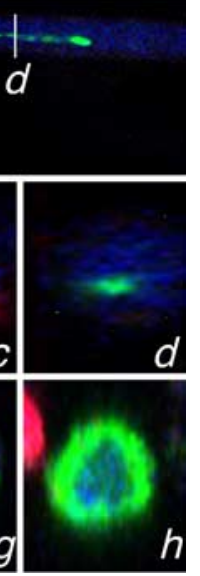

glial layers seems to be intact in $n r x I V$ mutants in addition to the lack of septate junctions, this suggests that most of the bloodbrain barrier function is conveyed by the subperineurial glial cells and here in particular by the septate junctions formed between these cells (supplemental Fig. 4, available at www.jneurosci.org as supplemental material). Compared with neurexinIV mutants, we also determined weaker uptake of $10 \mathrm{kDa}$ dextran into the CNS of moody mutant embryos which correlates with the reduced number of septae found in the septate junctions of this mutant (Schwabe et al., 2005) (Fig. $8 M, P$ ).

\section{Septate junction independent blood- brain barrier components}

To test for other putative components of the blood-brain barrier in addition to septate junctions, we used differently sized labeled dextran molecules. After injection of a labeled $70 \mathrm{kDa}$ dextran into $\mathrm{gcm}$ mutants high levels of fluorescence were immediately detected in the CNS (Fig. 8E). However, in contrast to the injection of a $10 \mathrm{kDa}$ dextran, it took $\sim 20$ min before comparable amounts of fluorescence were detectable in mutant neurexinIV embryos demonstrating that additional barrier mechanisms exist (Fig. $8 \mathrm{H}$, supplemental Fig. 5, available at www.jneurosci.org as supplemental material). Commercially available dextrans of 10 or $70 \mathrm{kDa}$ are either neutral or negatively charged. To compare the role of charge in penetration of the blood-brain barrier we injected both forms of $70 \mathrm{kDa}$ in neurexinIV mutant embryos. As no difference was observed in these experiments we conclude that charge is only a minor factor regarding the tightness of the septate junction independent component of the blood-brain barrier (data not shown).

To test how the blood-brain barrier seals the nervous system from even larger particles, we injected a $500 \mathrm{kDa}$ anionic dextran with a size of $\sim 26 \mathrm{~nm}$ in diameter (Luby-Phelps et al., 1986). In comparison, GFP has a diameter of $\sim 10 \mathrm{~nm}$ (Ormo et al., 1996). When $\mathrm{gcm}$ mutant embryos were injected, the neuropile immediately took up the injected dextran indicating that even large particles can easily penetrate into the nervous system in the absence of glial cells (Fig. $8 F$ ). When we injected $500 \mathrm{kDa}$ dextran into neurexinIV mutant animals, dye penetration was significantly reduced, corroborating the notion that not only septate junctions of the subperineurial cells contribute to the physiology of the blood-brain barrier (Fig. 8I). When we injected the 500 $\mathrm{kDa}$ dye in moody mutant animals, dye penetration was further reduced (Fig. 8O). In summary, the formation of the bloodbrain barrier appears to depend mostly on the integrity of the septate junctions formed by the subperineurial glial cell layer, but large molecules appear to be retained also by other barriers.

\section{Screening for genes required for blood-brain} barrier formation

The above findings allow us to test for further components involved in the formation or maintenance of the blood-brain 
barrier. In a first step we asked whether additional proteins associated with septate junctions in epithelial cells are required to set up a functional barrier. We injected labeled dextran molecules into embryos lacking neurexinIV, neuroglian, nervana2, contactin or coracle. For coracle and nervana2 mutants we obtained penetration phenotypes comparable with what is seen for mutant neurexinIV animals. Embryos lacking neuroglian function have a slightly less pronounced penetration phenotype suggesting that septate junctions in the nervous system are organized in a similar manner as in the epithelial tissues (supplemental Fig. 6, available at www.jneurosci.org as supplemental material). Contactin was shown previously to be required for normal barrier function and for the normal cell surface expression of NeurexinIV (Faivre-Sarrailh et al., 2004). In our hands, we found that the blood-brain barrier of embryos homozygous for a contactin deficiency was less affected as in mutant neurexinIV embryos suggesting that Contactin does fulfill an auxiliary function in the blood-brain barrier as it was described for the epithelium (Faivre-Sarrailh et al., 2004) (supplemental Fig. 6, available at www.jneurosci.org as supplemental material).

In addition, we tested whether Claudin-

type proteins that, based on work in mammalian systems confer size selectivity to endothelial or epithelial barriers (Tepass, 2003; Furuse and Tsukita, 2006; Van Itallie and Anderson, 2006), are required for Drosophila blood-brain barrier formation. In the Drosophila genome six different Claudin-like proteins have been identified (Wu et al., 2004). Two of these proteins, Sinuous and Megatrachea, have been shown to have a function in the epithelial septate junction dependent paracellular diffusion barrier (Behr et al., 2003; Wu et al., 2004). Both proteins are also required for the integrity of the blood-brain barrier and homozygous mutant embryos allowed penetration of the 10 and $70 \mathrm{kDa}$ dyes comparable with moody mutant embryos, whereas penetration of the $500 \mathrm{kDa}$ dextran was not observed (for sinuous see Fig. $8 \mathrm{~K}, L, P$ ). To test a possible contribution of the other four Claudin-like proteins we injected $10 \mathrm{kDa}$ dextran into embryos carrying chromosomal deficiencies removing these genes (for details, see Materials and Methods). In all cases no disruption of the bloodbrain barrier was observed, suggesting that these Claudin-like proteins are not needed for blood-brain barrier function (data not shown).

\section{Discussion}

A hallmark of any complex organized nervous system is its tight insulation against high ion concentrations in the extracellular fluids. This holds true for the mammalian blood-brain-barrier as well as for the much simpler barrier insulating the invertebrate nervous system where the high concentration of potassium in the hemolymph would impede any regulated electrical conductance (Carlson et al., 2000; Daneman and Barres, 2005).

Fast neuronal conductance requires a tight electrical insulation of the axons and in the mammalian nervous system, myelin and saltatory conductance evolved (Poliak and Peles, 2003; Sher- man and Brophy, 2005). Arthropods have not evolved saltatory conductance, but they are nevertheless in need for fast electrical conductance. In this respect it is not surprising that in marine shrimps myelin-like structures have been described previously (Davis et al., 1999; Weatherby et al., 2000). Drosophila follows two different and seemingly independent strategies to ensure fast conductance. In some central neuronal networks large caliber axons develop (Allen et al., 1998), whereas in the peripheral nervous system axons are insulated by several glial sheaths to ensure insulation. Initially, at the beginning of larval life, the different sensory and motor axons are kept as separate fascicles within the segmental nerves, suggesting there might be some degree of electrical cross talk within the different modalities. As the larva matures, the inner wrapping glia starts to grow around single axons, which may allow more sophisticated movements of the wandering larvae.

Whereas the wrapping glia insulates individual axons do perineurial and subperineurial glia insulate the entire nervous system and set up the blood-brain-barrier. Genetic experiments and ultrastructural studies have long indicated that septate junctions provide the most effective part of this barrier (Auld et al., 1995; Baumgartner et al., 1996; Carlson et al., 2000). Indeed, the subperineurial cell are formed early in development and these cells are connected by septate junctions from late embryonic stages onwards (Schwabe et al., 2005). Using Gal4 driver strains specific to the subperineurial cells as well as in vivo septate junction markers (Edenfeld et al., 2006), we confirm that during larval life the subperineurial cells do not divide but grow enormously large in size (Sepp et al., 2000; Silies et al., 2007). Septate junctions formed by the subperineurial cells are mostly found in interdigitated zones of cell-cell contact. Cell division would likely require disintegration of septate junctions and thus result in a temporal 

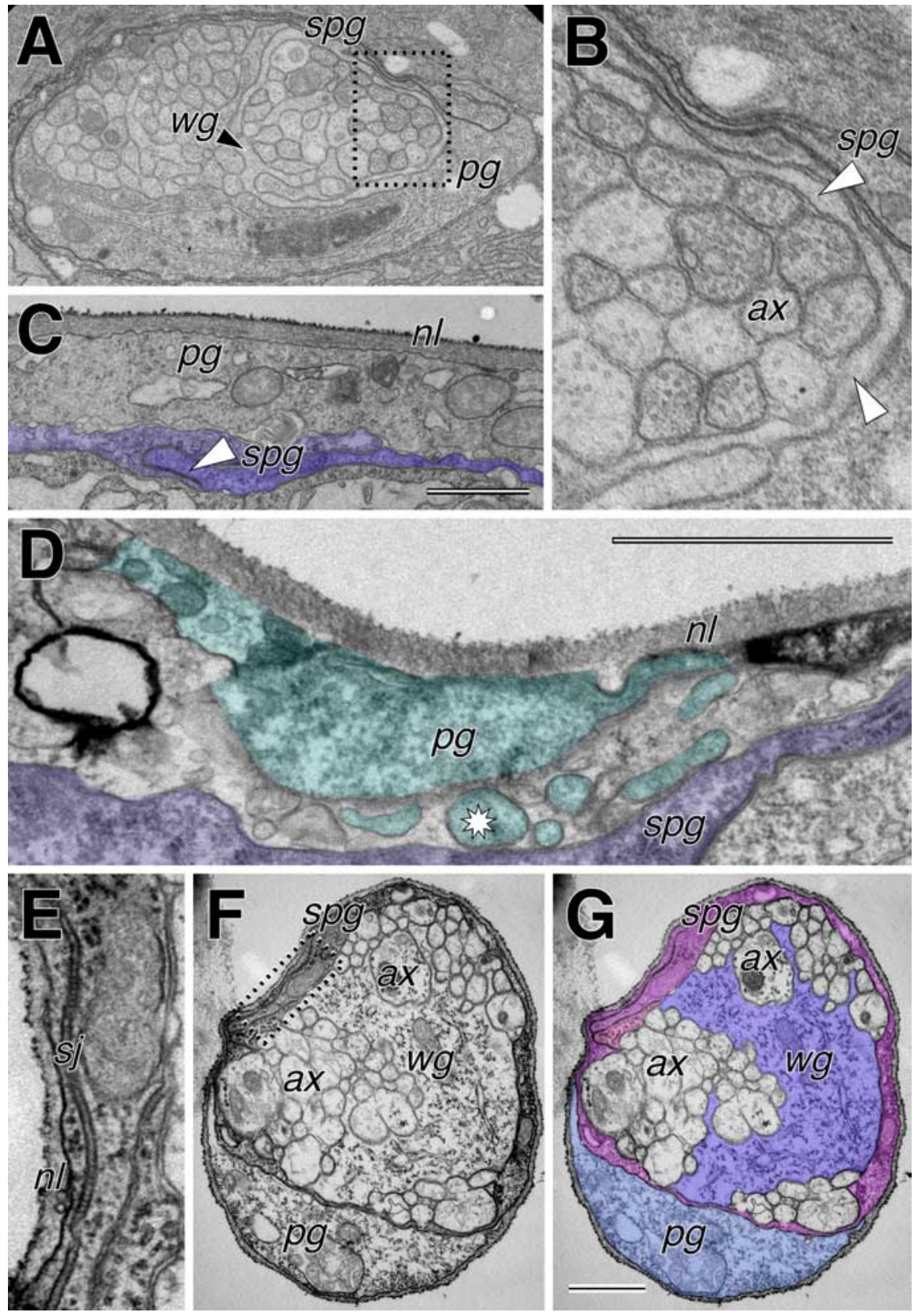

Figure 5. Ultrastructural morphology of perineurial and subperineurial cells. $A-G$, The figure shows electron micrographs of stage 16 embryonic nerves $(\boldsymbol{A}, \boldsymbol{B})$, first larval instar nerves $(\boldsymbol{E}-\boldsymbol{G})$, and third instar ventral nerve cord $(\boldsymbol{C}, \boldsymbol{D}) . \boldsymbol{A}$, In a peripheral nerve of a stage 16 nerve, perineurial $(\mathrm{pg})$ and subperineurial glial cells $(\mathrm{spg})$ are tightly associated with the axonal fascicles. The wrapping glia (wg) does not ensheath individual axons. The boxed area is shown in magnification in $\boldsymbol{B}$. $\boldsymbol{B}$, No glial processes can be detected within the fascicle. The axons are in direct contact with the subperineurial glia (spg) that forms a thin layer around the fascicle (arrowheads). C, In the CNS of a third instar larvae the subperineurial glia (light blue shading) is characterized by its flat appearance. Septate junctions can only be recognized in this glial layer (arrowhead). A thickneural lamella (nl) covers the nervous system. $\boldsymbol{D}$, In the perineurial glial cell layer (light green shading), numerous cell protrusions can be seen (asterisk). These processes never invade into the subperineurial layer. $\boldsymbol{E}$, In a first instar larval nerve, septate junctions are formed by the subperineurial cells. The image corresponds to the dotted area in $\boldsymbol{F}$. $\boldsymbol{F}$, Only few perineurial glial cells are found along the nerve. They do not fully cover the subperineurial cells as they do in later developmental stages. The wrapping glia has not yet started to individually ensheath every axon. G, The different glial cells are highlighted by shading. nl, Neural lamella; pg, perineurial glia; spg, subperineurial glia; sj, septate junction; wg, wrapping glia; ax, axons. Scale bars: $1 \mu \mathrm{m}$.

opening of the blood-brain barrier, which would be deleterious for the animal. This is in agreement with previous findings that Gliotactin expressing cells, forming septate junctions, do not divide during larval live (Sepp et al., 2000; Schulte et al., 2003, 2006).
The outermost glial cell layer is formed by the perineurial cells. Although these cells have long been described, their origin is still a matter of debate (Edwards et al., 1993; Schmid et al., 1999). In EM micrographs of late embryonic staged peripheral nerves some perineurial cells can be detected apically to the subperineurial cells. These glial cells divide during larval life and generate a large number of fine cell protrusions that cover the subperineurial cells. One function of the perineurium might be to influence the development and/or the tightness of the subperineurial layer. A comparable cellular function has been attributed to the astrocytes in the mammalian nervous system (Abbott et al., 2006). Alternatively, the perineurial glial cells might provide a cellular basis for the response to injury (Smith et al., 1987). Unfortunately, we have to date no specific driver strains that allow manipulation of this glial cell population. Interestingly, a reverse relationship between subperineurial and perineurial cells has been suggested previously as subperineurial expression of activated Ras or PI3K (phosphoinositide 3-kinase) resulted in an thickening of the perineurial sheath (Lavery et al., 2007).

Additionally, the fray gene has been shown to be required for normal axonal ensheathment (Leiserson et al., 2000). Interestingly the mutant phenotype could be rescued by expressing fray using three different Gal4 drivers (Leiserson et al., 2000). After the analysis of the specificity of these drivers ( $M z 317$, subperineurial glia and weak wrapping glia; $M z 709$, all glial cell types; gliotactinGal4, subperineurial glia) (data not shown), we conclude that fray is expressed in subperineurial glia and controls axonal ensheathment of wrapping glia in a noncell autonomous manner.

Given the different cellular barriers described in this report, questions arise concerning the functional contributions of the different layers. Here we have performed kinetic studies that supported the importance of the septate junctions in particular for small components. Animals lacking septate junctions are as leaky to a $10 \mathrm{kDa}$ dextran as animals lacking all glial cell layers. However, when it comes to larger molecules, the relevance of the other cell layers becomes obvious. Although a $500 \mathrm{kDa}$ dextran can easily penetrate into the nervous system of a glial cells missing embryo, its leakage into the nervous system of a neurexinIV mutant lacking septate junctions is greatly reduced. Thus, the other layers contribute to the function of the blood-brain barrier. Because a continuous perineurium is not fully formed in first instar larvae, the barrier function has to be assigned to the neural lamella and the inner glial layer. There are several reports 
showing that the neural lamella can act as an efficient filter for heavy metal ions (Carlson et al., 2000). Possibly, large molecules such as the $500 \mathrm{kDa}$ dextran are also trapped in this ECM. Alternatively, large particles are stopped by the diffusion barrier established by the normal cell-cell contacts between subperineurial cells and inner glial cell types like wrapping glia in the peripheral nerves and cortex and neuropile glia in the CNS.

The diffusion barrier provided by glial cells or epithelial sheaths is generated by special junctional complexes that help to tightly associate the involved cells. Drosophila epithelia as well as glial cells are characterized by septate junctions (Tepass and Hartenstein, 1994). Quite similar structures are also found at the mammalian paranodal junctions, which provide the structural basis for the tight electrical insulation of the nerve. A core component of the mammalian axoglial septate junctions is the NeurexinIV homolog Caspr that together with its binding partners, Contactin and Neurofascin155, sets up a tripartite adhesion complex at the paranode (Bhat et al., 2001; Girault and Peles, 2002; Poliak and Peles, 2003; Sherman and Brophy, 2005).

The function of this complex appears conserved in Drosophila, although there are some notable differences. The Caspr homolog NeurexinIV is expressed by glial cells as are Contactin and the Neurofascin155 homolog Neuroglian (FaivreSarrailh et al., 2004; Banerjee et al., 2006). As a consequence, in the fly septate junctions are formed between glial cells, whereas they are formed between neuronal and glial membranes in the mammalian system. The Caspr/Contactin/Neurofascin 155 complex seals the paranodal junction and a similar function has been attributed to this protein complex in the invertebrate blood-brain barrier (Bhat, 2003). Here, we found a less pronounced function of Contactin compared with NeurexinIV for the blood-brain barrier establishment, corroborating findings made in embryonic epithelia (Faivre-Sarrailh et al., 2004).

Another prominent component of the junctional complexes are the Claudin proteins. In mammals, members of these four transmembrane domain proteins are associated with tight junctions that are often considered to be functionally equivalent to the invertebrate septate junctions (Furuse and Tsukita, 2006). In Drosophila two Claudin-like proteins have been described to be required for formation of normal epithelial barrier formation (Behr et al., 2003; Wu et al., 2004). Here, we show that both Sinuous and Megatrachea are also needed for the establishment of normal blood-brain barrier formation. Similarly, it was shown previously that mammalian claudin 5 is a major
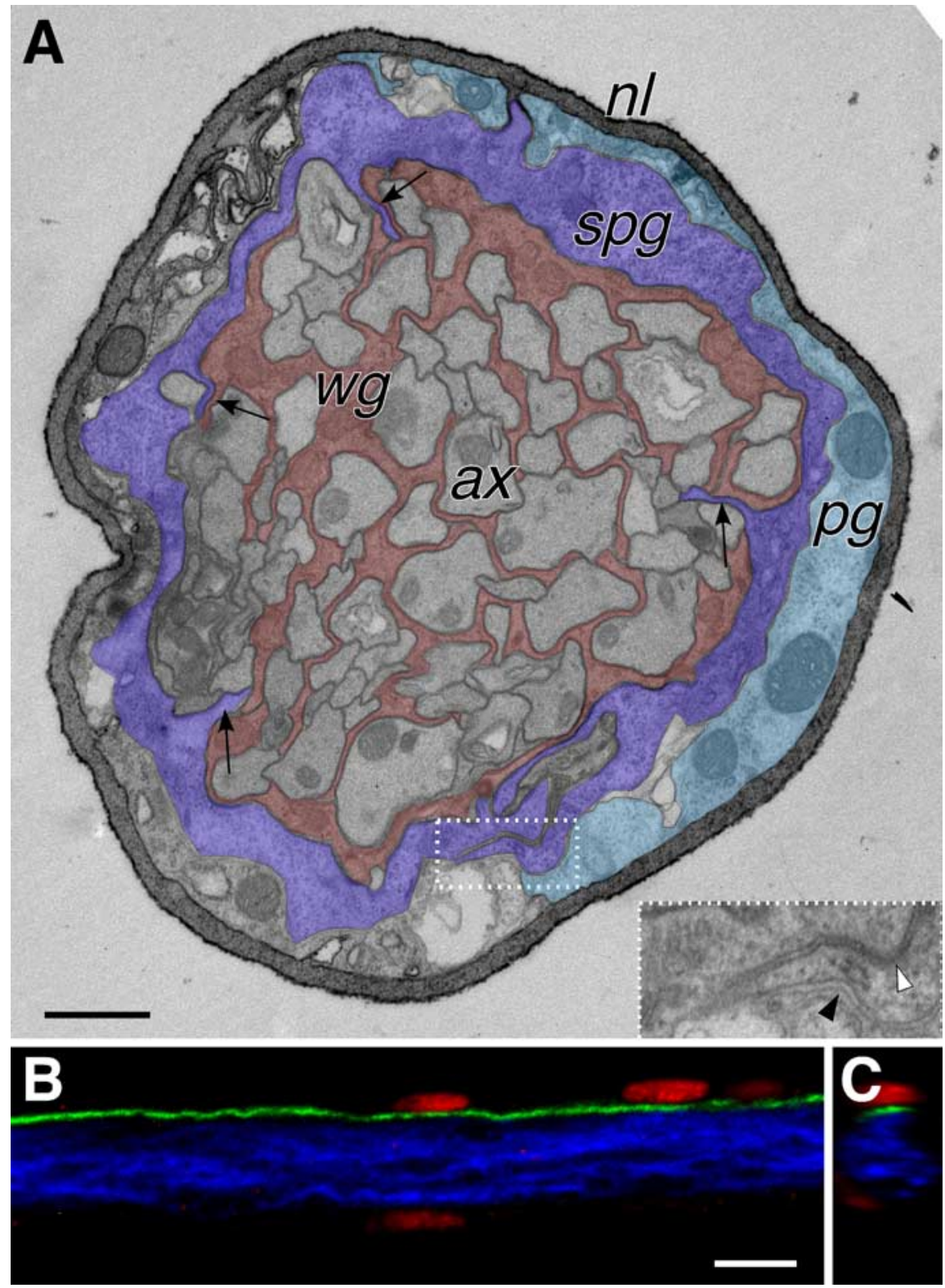

Figure 6. Three glial cell layers are present in the larval nerve. $A$, Electron micrograph of a third larval instar peripheral nerve. The neural lamella (nl) has the same size throughout the nerve circumference. Below are the perineurial glial cells (pg, one cell is highlighted by light blue shading) that show various indentations and profiles of small cell protrusions. The fascicle is encircled by one subperineurial glial cell that forms only short processes toward the axon fascicle (spg, arrows, the cell is labeled in blue). The subperineurial glia forms autocellular septate junctions (boxed area and magnification; white arrowhead points to septate junctions; black arrowhead points to septate junction-free cell-cell contact). Within the fascicle, usually two to three glial cell profiles can be detected (one profile is highlighted in red). $\boldsymbol{B}$, Third instar larval nerves were stained for HRP (blue), Repo expression (red), and Dlg:GFP expression (green). Scale bar, $1 \mu \mathrm{m} . \boldsymbol{B}, \boldsymbol{C}$, Lateral and orthogonal (C) view of a larval nerve expressing a Dlg:GFP fusion protein under the control of the SPG:Gal 4 driver. GFP expression accumulates at the septate junctions formed by the subperineurial glial cell. component of tight junctions of brain endothelial cells. claudin5 mutant mice show no structural or ultrastructural deficits, but have an impaired blood-brain barrier (Morita et al., 1999; Nitta et al., 2003). The association of Claudins integrated in opposing membranes is thought to provide pores that can control the paracellular diffusion of small molecules. Although Drosophila Sinuous and Megatrachea clearly contribute to the barrier function, it is inconceivable that fly Claudins traverse the $20 \mathrm{~nm}$ wide septate gap to form a Claudin pore as it is discussed for the vertebrate Claudins (Furuse and Tsukita, 2006; Van Itallie and Anderson, 

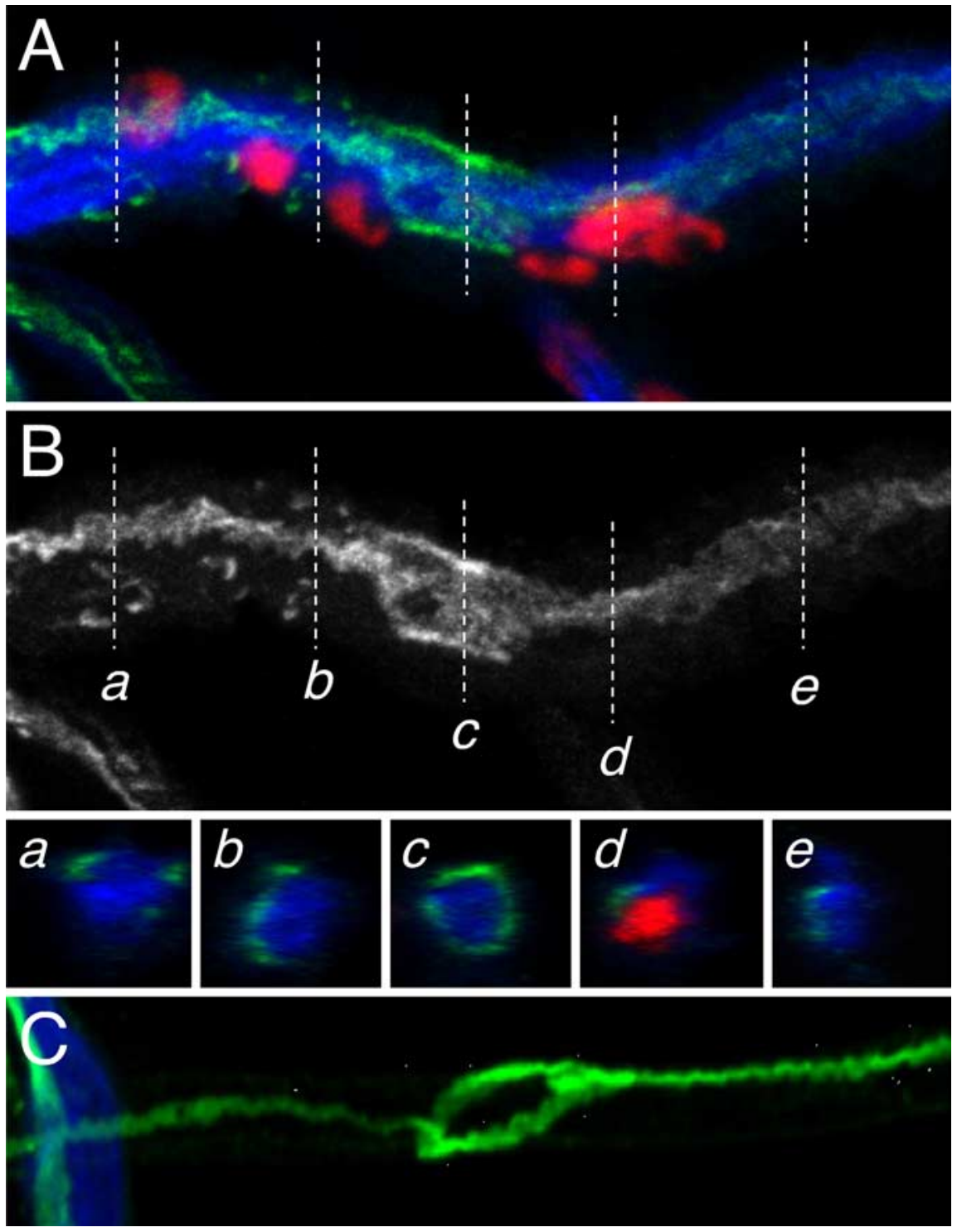

Figure 7. Septate junction formation in the PNS. Septate junction formation is followed using the neurexin/V GFP gene trap insertion (green) and confocal analysis. Glial cell nuclei are stained in red (Repo staining) whereas axonal membranes are shown in blue (HRP staining). $\boldsymbol{A}$, Confocal analysis of the entire nerve, with only the NeurexinIV::GFP expression shown in $\boldsymbol{B}$. The dotted lines indicate the orthogonal sections shown under $(\boldsymbol{a}-\boldsymbol{e})$. In level $\boldsymbol{c}$, septate junctions are formed between two glial cells resulting in a ring-like structure. $C$, Note the extended and broadened expression of NeurexinIV::GFP, which is in contrast to the discrete NeurexinIV::GFP expression in a corresponding contact point in the tracheal system.

2006). It has also been suggested that invertebrate Claudins might have lost their pore-like functions and exert only signaling function to establish the barrier (Van Itallie and Anderson, 2006).

Such a signaling function may control the size selectivity of the barrier and indeed sinuous mutants show only a weak barrier phenotype comparable with moody mutants, correlating with reduced septate junctions (Wu et al., 2004; Bainton et al., 2005; Schwabe et al., 2005). Here, we demonstrated that a loss of septate junctions associated with neurexinIV mutants results in breakdown of the blood-brain barrier comparable with what is observed in animals lacking all glial cells. However, additional mechanisms are in place to control the paracellular diffusion of larger particles. A $500 \mathrm{kDa}$ dextran can easily penetrate the nervous system of a glial cells missing embryo but cannot enter a nerve cord only lacking septate junctions.

\section{References}

Abbott NJ, Ronnback L, Hansson E (2006) Astrocyte-endothelial interactions at the blood-brain barrier. Nat Rev Neurosci 7:41-53.

Allen MJ, Drummond JA, Moffat KG (1998) Development of the giant fiber neuron of Drosophila melanogaster. J Comp Neurol 397:519-531.

Auld VJ, Fetter RD, Broadie K, Goodman CS (1995) Gliotactin, a novel transmembrane protein on peripheral glia, is required to form the blood-nerve barrier in Drosophila. Cell 81:757-767.

Bachmann A, Timmer M, Sierralta J, Pietrini G, Gundelfinger ED, Knust E, Thomas U (2004) Cell type-specific recruitment of Drosophila Lin-7 to distinct MAGUK-based protein complexes defines novel roles for Sdt and Dlg-S97. J Cell Sci 117:1899-1909.

Bainton RJ, Tsai LT, Schwabe T, DeSalvo M, Gaul U, Heberlein U (2005) moody encodes two GPCRs that regulate cocaine behaviors and blood-brain barrier permeability in Drosophila. Cell 123:145-156.

Banerjee S, Pillai AM, Paik R, Li J, Bhat MA (2006) Axonal ensheathment and septate junction formation in the peripheral nervous system of Drosophila. J Neurosci 26:3319-3329.

Baumgartner S, Littleton JT, Broadie K, Bhat MA, Harbecke R, Lengyel JA, Chiquet-Ehrismann R, Prokop A, Bellen HJ (1996) A Drosophila neurexin is required for septate junction and blood-nerve barrier formation and function. Cell 87:1059-1068.

Behr M, Riedel D, Schuh R (2003) The claudinlike megatrachea is essential in septate junctions for the epithelial barrier function in Drosophila. Dev Cell 5:611-620.

Bellen HJ, Lu Y, Beckstead R, Bhat MA (1998) Neurexin IV, caspr and paranodin-novel members of the neurexin family: encounters of axons and glia. Trends Neurosci 21:444-449.

Bhat MA (2003) Molecular organization of axoglial junctions. Curr Opin Neurobiol 13:552-559.

Bhat MA, Rios JC, Lu Y, Garcia-Fresco GP, Ching W, St Martin M, Li J, Einheber S, Chesler M, Rosenbluth J, Salzer JL, Bellen HJ (2001) Axon-glia interactions and the domain organization of myelinated axons requires neurexin IV/Caspr/Paranodin. Neuron 30:369-383.

Carlson SD, Juang JL, Hilgers SL, Garment MB (2000) Blood barriers of the insect. Annu Rev Entomol 45:151-174.

Daneman R, Barres BA (2005) The blood-brain barrier-lessons from moody flies. Cell 123:9-12.

Davis AD, Weatherby TM, Hartline DK, Lenz PH (1999) Myelin-like sheaths in copepod axons. Nature 398:571.

Ebersole TA, Chen Q, Justice MJ, Artzt K (1996) The quaking gene product necessary in embryogenesis and myelination combines features of RNA binding and signal transduction proteins. Nat Genet 12:260-265.

Edenfeld G, Stork T, Klambt C (2005) Neuron-glia interaction in the insect nervous system. Curr Opin Neurobiol 15:34-39.

Edenfeld G, Volohonsky G, Krukkert K, Naffin E, Lammel U, Grimm A, Engelen D, Reuveny A, Volk T, Klambt C (2006) The Splicing Factor Crooked Neck Associates with the RNA-Binding Protein HOW to Control Glial Cell Maturation in Drosophila. Neuron 52:969-980.

Edwards JS, Swales LS, Bate M (1993) The differentiation between neuroglia and connective tissue sheath in insect ganglia revisited: the neural lamella and perineurial sheath cells are absent in a mesodermless mutant of Drosophila. J Comp Neurol 333:301-308. 


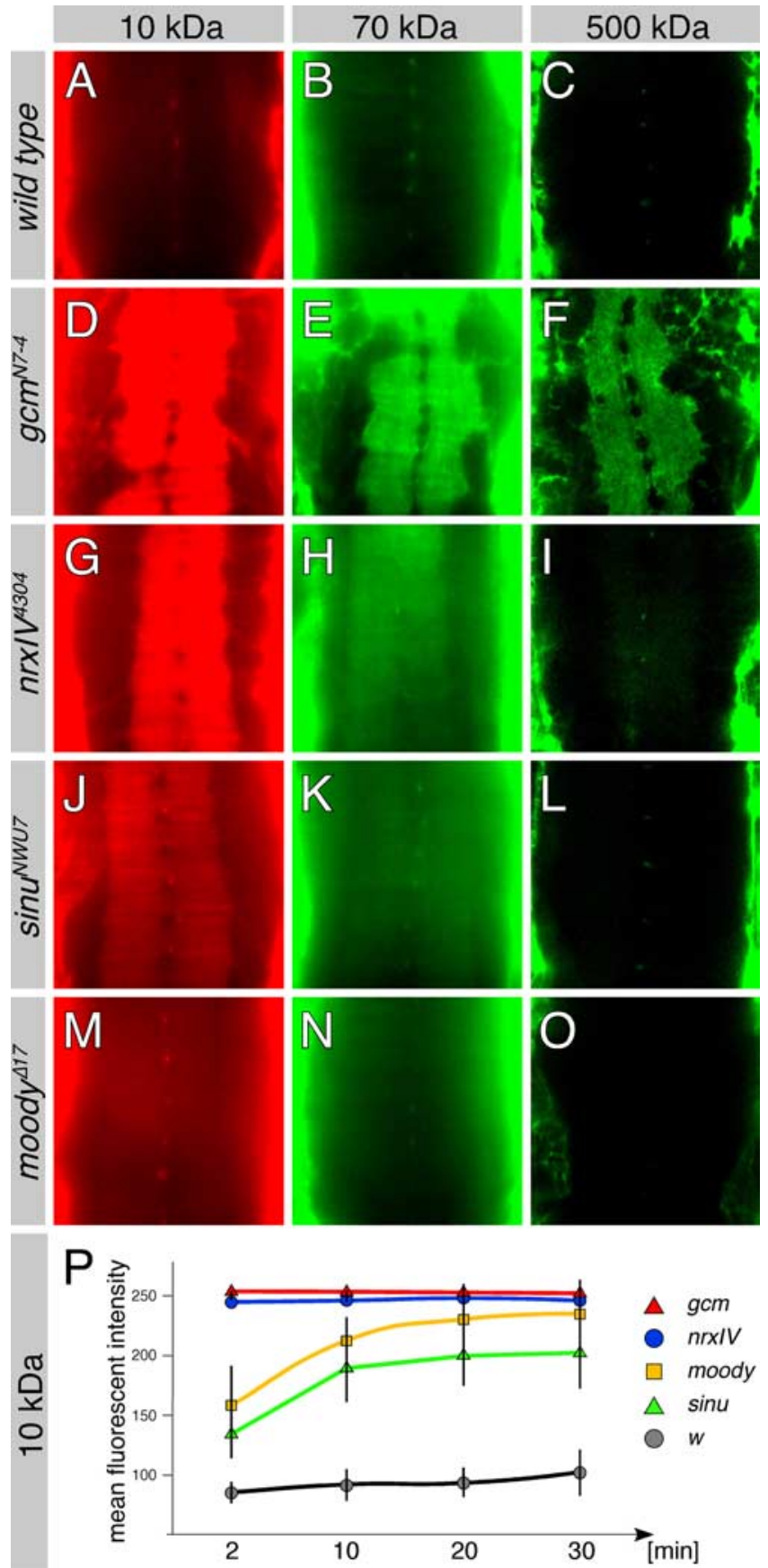

Figure 8. Different glial layers contribute differently to the blood-brain barrier. Differently sized fluorescent-labeled dextran molecules were injected into stage 17 embryos of the following genotypes: $\mathrm{w}^{1118} ; \mathrm{gcm}^{N 7-4} ; \mathrm{nrXl}^{4304} ; \sin \mathrm{u}^{\mathrm{NWU7}}$, and moody ${ }^{\Delta 17}$. Images shown were taken $2 \mathrm{~min}$ after injection. The differently sized dextrans are indicated; the images after injection of 10 and $70 \mathrm{kDa}$ dextran were taken with a Zeiss LSM 5 Live microscope. The scan mode was set at a speed of four frames per second. The images after injection of $500 \mathrm{kDa}$ dextran were taken with a Zeiss LSM 510 Meta. Homozygous embryos were recognized using GFP-labeled balancer chromosomes. $\boldsymbol{A}-\boldsymbol{C}, A w^{1118}$ embryo is used as wild-type control. $\boldsymbol{D}-\boldsymbol{F}$, In $g(m$ mutants, all dyes readily penetrated into the nerve cord. $\mathbf{G}-\mathbf{I}, \operatorname{In} n r x \mid V$ mutant embryos, larger dextran molecules did not penetrate as easily. $\mathbf{J}-\mathbf{0}$, Dye penetration in sinuous mutants is similar to penetration in moody mutants. $\boldsymbol{P}$, Quantification of $10 \mathrm{kDa}$ dextran uptake over $30 \mathrm{~min}$ in the mutants indicated.

Faivre-Sarrailh C, Banerjee S, Li J, Hortsch M, Laval M, Bhat MA (2004) Drosophila contactin, a homolog of vertebrate contactin, is required for septate junction organization and paracellular barrier function. Development 131:4931-4942.
Freeman MR, Doherty J (2006) Glial cell biology in Drosophila and vertebrates. Trends Neurosci 29:82-90.

Furuse M, Tsukita S (2006) Claudins in occluding junctions of humans and flies. Trends Cell Biol 16:181-188.

Genova JL, Fehon RG (2003) Neuroglian, Gliotactin, and the $\mathrm{Na}^{+} / \mathrm{K}^{+}$ATPase are essential for septate junction function in Drosophila. J Cell Biol 161:979-989.

Girault JA, Peles E (2002) Development of nodes of Ranvier. Curr Opin Neurobiol 12:476-485.

Granderath S, Klämbt C (1999) Genetic analysis of gliogenesis in Drosophila. In: Glial cell development (Jessen K, Richardson W, eds), pp 245-262. Oxford: Oxford UP.

Hosoya T, Takizawa K, Nitta K, Hotta Y (1995) glial cells missing: a binary switch between neuronal and glial determination in Drosophila. Cell 82:1025-1036.

Hummel T, Krukkert K, Roos J, Davis G, Klambt C (2000) Drosophila Futsch/22C10 is a MAP1B-like protein required for dendritic and axonal development. Neuron 26:357-370.

Hummel T, Attix S, Gunning D, Zipursky SL (2002) Temporal control of glial cell migration in the Drosophila eye requires gilgamesh, hedgehog, and eye specification genes. Neuron 33:193-203.

Ito K, Urban J, Technau GM (1995) Distribution, classification and development of Drosophila glial cells during late embryogenesis. Roux's Arch Dev Biol 204:284-307.

Lamb RS, Ward RE, Schweizer L, Fehon RG (1998) Drosophila coracle, a member of the protein 4.1 superfamily, has essential structural functions in the septate junctions and developmental functions in embryonic and adult epithelial cells. Mol Biol Cell 9:3505-3519.

Lane NJ, Treherne JE (1972) Studies on perineural junctional complexes and the sites of uptake of microperoxidase and lanthanum in the cockroach central nervous system. Tissue Cell 4:427-436.

Lavery W, Hall V, Yager JC, Rottgers A, Wells MC, Stern M (2007) Phosphatidylinositol 3-kinase and Akt nonautonomously promote perineurial glial growth in Drosophila peripheral nerves. J Neurosci 27:279-288.

Lee BP, Jones BW (2005) Transcriptional regulation of the Drosophila glial gene repo. Mech Dev 122:849-862.

Lee T, Luo L (1999) Mosaic analysis with a repressible cell marker for studies of gene function in neuronal morphogenesis. Neuron 22:451-461.

Leiserson WM, Harkins EW, Keshishian H (2000) Fray, a Drosophila serine/ threonine kinase homologous to mammalian PASK, is required for axonal ensheathment. Neuron 28:793-806.

Lemke G (2001) Glial control of neuronal development. Annu Rev Neurosci 24:87-105.

Luby-Phelps K, Taylor DL, Lanni F (1986) Probing the structure of cytoplasm. J Cell Biol 102:2015-2022.

Morita K, Sasaki H, Furuse M, Tsukita S (1999) Endothelial claudin: claudin-5/TMVCF constitutes tight junction strands in endothelial cells. J Cell Biol 147:185-194.

Nave KA, Salzer JL (2006) Axonal regulation of myelination by neuregulin 1. Curr Opin Neurobiol 16:492-500.

Nitta T, Hata M, Gotoh S, Seo Y, Sasaki H, Hashimoto N, Furuse M, Tsukita S (2003) Size-selective loosening of the blood-brain barrier in claudin5-deficient mice. J Cell Biol 161:653-660.

Olofsson B, Page DT (2005) Condensation of the central nervous system in embryonic Drosophila is inhibited by blocking hemocyte migration or neural activity. Dev Biol 279:233-243.

Ormo M, Cubitt AB, Kallio K, Gross LA, Tsien RY, Remington SJ (1996) Crystal structure of the Aequorea victoria green fluorescent protein. Science 273:1392-1395.

Pereanu W, Shy D, Hartenstein V (2005) Morphogenesis and proliferation of the larval brain glia in Drosophila. Dev Biol 283:191-203.

Poliak S, Peles E (2003) The local differentiation of myelinated axons at nodes of Ranvier. Nat Rev Neurosci 4:968-980.

Ribeiro C, Neumann M, Affolter M (2004) Genetic control of cell intercalation during tracheal morphogenesis in Drosophila. Curr Biol 14:2197-2207.

Salvaterra PM, Kitamoto T (2001) Drosophila cholinergic neurons and processes visualized with Gal4/UAS-GFP. Brain Res Gene Expr Patterns 1:73-82.

Schmid A, Chiba A, Doe CQ (1999) Clonal analysis of Drosophila embryonic neuroblasts: neural cell types, axon projections and muscle targets. Development 126:4653-4689. 
Schulte J, Tepass U, Auld VJ (2003) Gliotactin, a novel marker of tricellular junctions, is necessary for septate junction development in Drosophila. J Cell Biol 161:991-1000.

Schulte J, Charish K, Que J, Ravn S, MacKinnon C, Auld VJ (2006) Gliotactin and Discs large form a protein complex at the tricellular junction of polarized epithelial cells in Drosophila. J Cell Sci 119:4391-4401.

Schwabe T, Bainton RJ, Fetter RD, Heberlein U, Gaul U (2005) GPCR signaling is required for blood-brain barrier formation in Drosophila. Cell 123:133-144.

Sepp KJ, Schulte J, Auld VJ (2000) Developmental dynamics of peripheral glia in Drosophila melanogaster. Glia 30:122-133.

Sherman DL, Brophy PJ (2005) Mechanisms of axon ensheathment and myelin growth. Nat Rev Neurosci 6:683-690.

Sidman RL, Dickie MM, Appel SH (1964) Mutant Mice (Quaking and Jimpy) with Deficient Myelination in the Central Nervous System. Science 144:309-311.

Silies M, Yuva Y, Engelen D, Aho A, Stork T, Klämbt C (2007) Glial cell migration in the eye disc. J Neurosci 27:13130-13139.

Smith PJ, Howes EA, Treherne JE (1987) Mechanisms of glial regeneration in an insect central nervous system. J Exp Biol 132:59-78.

Stollewerk A, Klämbt C (1997) The midline glial cells are required for compartmentalisation of axon commissures in the embryonic CNS of Drosophila. Dev Genes Evol 207:401-409.

Stollewerk A, Klambt C, Cantera R (1996) Electron microscopic analysis of Drosophila midline glia during embryogenesis and larval development using beta-galactosidase expression as endogenous cell marker. Microsc Res Tech 35:294-306.

Strigini M, Cantera R, Morin X, Bastiani MJ, Bate M, Karagogeos D (2006) The IgLON protein Lachesin is required for the blood-brain barrier in Drosophila. Mol Cell Neurosci.

Struhl G, Basler K (1993) Organizing activity of wingless protein in Drosophila. Cell 72:527-540.
Sun B, Xu P, Salvaterra PM (1999) Dynamic visualization of nervous system in live Drosophila. Proc Natl Acad Sci USA 96:10438-10443.

Tepass U (2003) Claudin complexities at the apical junctional complex. Nat Cell Biol 5:595-597.

Tepass U, Hartenstein V (1994) The development of cellular junctions in the Drosophila embryo. Dev Biol 161:563-596.

Treherne JE (1962) Transfer of substances between the blood and central nervous system in vertebrate and invertebrate animals. Nature 196:1181-1183.

Treherne JE, Pichon Y (1972) The insect blood-brain barrier. In: Advances in insect physiology (Treherne JE, Berridge MJ, Wigglesworth VB, eds), pp 257-308. London: Academic.

Van De Bor V, Giangrande A (2002) glide/gcm: at the crossroads between neurons and glia. Curr Opin Genet Dev 12:465-472.

Van Itallie CM, Anderson JM (2006) Claudins and epithelial paracellular transport. Annu Rev Physiol 68:403-429.

Vincent S, Vonesch JL, Giangrande A (1996) Glide directs glial fate commitment and cell fate switch between neurones and glia. Development 122:131-139.

Weatherby TM, Davis AD, Hartline DK, Lenz PH (2000) The need for speed. II. Myelin in calanoid copepods. J Comp Physiol A Neuroethol Sens Neural Behav Physiol 186:347-357.

Wong AM, Wang JW, Axel R (2002) Spatial representation of the glomerular map in the Drosophila protocerebrum. Cell 109:229-241.

Wu VM, Schulte J, Hirschi A, Tepass U, Beitel GJ (2004) Sinuous is a Drosophila claudin required for septate junction organization and epithelial tube size control. J Cell Biol 164:313-323.

Xiong WC, Okano H, Patel NH, Blendy JA, Montell C (1994) repo encodes a glial-specific homeo domain protein required in the Drosophila nervous system. Genes Dev 8:981-994.

Younossi-Hartenstein A, Salvaterra PM, Hartenstein V (2003) Early development of the Drosophila brain: IV. Larval neuropile compartments defined by glial septa. J Comp Neurol 455:435-450. 